\title{
"Impact of dust on tropospheric chemistry over polluted regions: a case study of the Beijing megacity" published in Atmos. Chem. Phys., 10, 3855-3873, 2010
}

S. Zhu ${ }^{1,2}$, T. Butler ${ }^{2}$, R. Sander ${ }^{2}$, J. Ma ${ }^{1}$, and M. G. Lawrence ${ }^{2,3}$

${ }^{1}$ Chinese Academy of Meteorological Sciences, Beijing, China

${ }^{2}$ Max Planck Institute for Chemistry, Mainz, Germany

${ }^{3}$ University of Mainz, Mainz, Germany

Unfortuantely, there are some mistakes in the authors' affiliations. The correct affilations are:

S. Zhu ${ }^{1,2,3}$, T. Butler ${ }^{3}$, R. Sander ${ }^{3}$, J. Ma ${ }^{1}$, and M. G. Lawrence ${ }^{3,4}$

${ }^{1}$ Key Laboratory for Atmospheric Chemistry, Chinese Academy of Meteorological Sciences, Beijing, China

${ }^{2}$ Graduate University of Chinese Academy of Sciences, Beijing, China

${ }^{3}$ Max Planck Institute for Chemistry, Mainz, Germany

${ }^{4}$ University of Mainz, Mainz, Germany 